\title{
Marul Tohumunun Bazı Fiziko-Mekanik Özelliklerinin Belirlenmesi
}

\author{
İpek Çekim ${ }^{1 *}$ Cengiz Özarslan ${ }^{2}$
}

\author{
${ }^{1}$ Aydın Adnan Menderes Üniversitesi, Fen Bilimleri Enstitüsü, Tarım Makinaları Anabilim Dalı, Aydın \\ ${ }^{2}$ Aydın Adnan Menderes Üniversitesi, Ziraat Fakültesi, Biyosistem Mühendisliği Bölümü, Aydın \\ *Sorumlu yazar: ipekbiyosistem @gmail.com \\ ${ }^{1}$ https://orcid.org/0000-0002-3828-7671, ${ }^{2}$ https://orcid.org/0000-0002-1156-2362
}

Geliş Tarihi: 12.09.2019

Kabul Tarihi: 06.05.2020

\section{$\ddot{O} z$}

Marul tohumlarının fiziko-mekanik özellikleri; hasat, taşıma, temizleme, ayırma, paketleme, tohum kaplama, depolama ve işleme ekipmanlarının tasarımı için önemlidir. Bu çalışmada marul tohumunun bazı fiziko-mekanik özelliklerinin belirlenmesi amaçlanmıştır. Bu amaç doğrultusunda marul tohumlarının geometrik, gravimetrik, aerodinamik, sürtünme ve mekanik özellikleri belirlenmiştir. Ölçüm sonuçlarına göre \% 8,09 (kuru bazda) nem içeriğine sahip marul tohumlarının uzunluk, genişlik ve kalınlık ortalamaları sırasıyla 3,36 mm, 0,84 $\mathrm{mm}$ ve $0,54 \mathrm{~mm}$, projeksiyon alanı $2,79 \mathrm{~mm}^{2}$ olarak ölçülmüş ve küresellik 0,34 olarak hesaplanmıştır. Marul

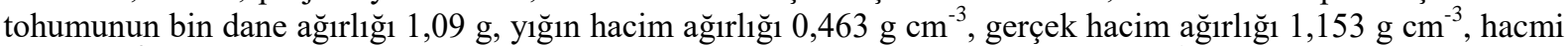
$0,871 \mathrm{~cm}^{3}$, porozitesi $\% 59,84$ olarak belirlenmiştir. Kritik hız değeri ise $3,46 \mathrm{~m} \mathrm{~s}^{-1}$ olarak ölçülmüştür. Statik sürtünme katsayısı paslanmaz çelik, alüminyum, kontrplak ve kauçuk olmak üzere dört farklı yüzeyde ölçülmüş olup sonuçlar sirasiyla 0,198,0,278, 0,346 ve 0,352 olarak bulunmuştur. Marul tohumunun dinamik yığılma açısı alüminyumda $18,99^{\circ}$, paslanmaz çelikte $20,33^{\circ}$, kontrplakta $20,34^{\circ}$ ve kauçukta $21,05^{\circ}$ olarak elde edilmiş, statik yı̆̆ılma açısı $22,5^{\circ}$ ve kabuk kırılma direnci ise $1,29 \mathrm{~kg}$ olarak belirlenmiştir.

Anahtar Kelimeler: Marul tohumu, porozite, kritik hız

\section{Determination of Some Physico-Mechanical Properties of Lettuce Seed}

\section{Abstract}

The physico-mechanical properties of lettuce seeds are essential for the design of equipment for harvesting, transporting, cleaning, separating, packing, seed coating, storing and processing. The aim of this study was to determine some physico-mechanical properties of lettuce seeds. The geometric, gravimetric, aerodynamic, and mechanical properties and friction characteristics of lettuce seeds were obtained. According to the results, the averages length, width and thickness of lettuce seeds with a moisture content of $8,09 \%$ d.b. were measured as $3,36 \mathrm{~mm}, 0,84 \mathrm{~mm}$ and $0,54 \mathrm{~mm}$, respectively with a projected area of $2,79 \mathrm{~mm}^{2}$. The sphericity of lettuce seeds was calculated as 0,34 . The thousand grain of mass, bulk density, true density, volume, and porosity of lettuce seeds were measured as $1,09 \mathrm{~g}, 0,463 \mathrm{~g} \mathrm{~cm}^{-3}, 1,153 \mathrm{~g} \mathrm{~cm}^{-3}, 0,871 \mathrm{~cm}^{3}$, and $59,84 \%$, respectively. The terminal velocity was measured as $3,46 \mathrm{~m} \mathrm{~s}^{-1}$. The static coefficient of friction was measured on four different surfaces, namely, stainless steel, aluminium, plywood and rubber. The results were found to be $0,198,0,278,0,346$ and 0,352 , respectively. The dynamic angle of repose of lettuce seeds was specified as $20,33^{\circ}, 18,99^{\circ}, 20,34^{\circ}$ and $21,05^{\circ}$ on same surfaces. In addition, the static response angle was $22,55^{\circ}$ and the shelling resistance was found as $1,29 \mathrm{~kg}$.

Keywords: Lettuce seed, porosity, terminal velocity

\section{Giriș}

Latince adı Lactuca sativa L. olan marul, yapraklı sebzeler grubunun en önemli sebzelerinden biri olarak kabul edilmekte ve dünya genelinde pek çok ülkede ticari olarak üretimi yapılmaktadır. Özellikle Asya, Avrupa, Kuzey ve Orta Amerika'da önemli bir ticari ürünüdür. Çin, ABD, İspanya, İtalya, Hindistan ve Japonya marul üretimi yapan başlica ülkelerdendir (Kristkova ve ark., 2008). Senelik bir kültür sebzesi olan marulun ülkemizde ise Ege, Marmara ve Akdeniz bölgelerinde ticari olarak üretimi yapılmaktadır. Açık tarla koşullarında üretim yapılabildiği gibi özellikle kış mevsimindeki yüksek fiyatlardan yararlanmak amacıyla sera ve alçak plastik tünellerde de marul üretimi yapılmaktadır. 2-3 ay gibi kısa bir üretim dönemine sahip olan marul, ülkemizde genellikle ikinci veya üçüncü ürün olarak ana sebze üretiminin ön veya arkasından yapılmaktadır.

Marul tohumları çeşit ve yetiştirme bölgelerine bağlı olarak çok az değişiklik göstermektedir (Şekil 1). Optimum koşullarda marul tohumları $\left(20^{\circ} \mathrm{C}\right)$ 4-7 günde çimlenirken fidelik ve tarla koşullarında ise sıcaklık optimum $18-21^{\circ} \mathrm{C}$ olmalıdır. Genelde yassı ve uzunluğuna oluklu, uç tarafı 
çıkıntılı olan marul tohumları 3-6 mm uzunluğunda $0,8-1,0 \mathrm{~mm}$ genişliğinde ve 0,3-0,6 mm kalınlığındadır. Tohum rengi ise kirli beyaz, sarı, krem, kahverengi ve siyaha yakın olabilmektedir. Tohumların bin dane ağırlığı 0,8-1,2 gramdır. Marul bitkisinde tohum verimi; çeşit, sıra arası ve sıra üzeri mesafeleri ile bakım koşullarına bağlı olarak değişmektedir. Optimum bakım koşullarında bir dekar alandan 50-75 kg tohum elde edilmektedir (Anonim, 2011).

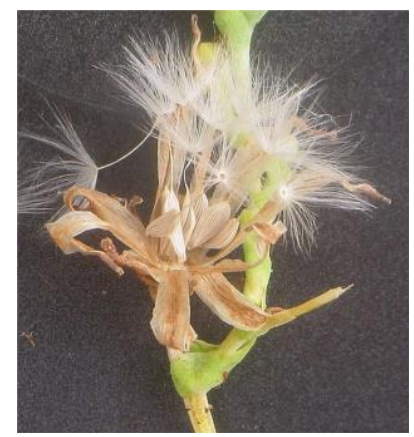

Şekil 1. Olgunlaşmış marul tohumları (Anonim, 2011)

Hasat ve harman işlemleri sonucunda elde edilen ürün içerisinde yer alan yabancı materyallerin ayrılmasında ve esas ürün tanelerinin sınıflandırılmasında belirgin ayırıcı karakteristik özelliklerden yararlanılmaktadır. Her bir tanenin yüzey özellikleri, iç ve biyolojik yapısı diğer bir taneden farklı olabilmekte ve bu farklılıkların fazla olması ayırma işleminin başarısını artırmaktadır (Yağcıŏglu, 1996).

Harman işlemi sonucunda elde edilen marul tohumu içerisinde farklı fiziksel özelliklere sahip yabanc1 materyaller bulunmaktadır (Şekil 2). Marul yetiştiriciliğinde ekim ve bakım faaliyetleri açısından safiyeti yüksek tohumluğun kullanılması büyük önem taşımaktadır. Yüksek safiyette tohum kullanıldığında ekimin kalitesi artmakta, ayrıca yabancı otların yaygınlaşması önlenmekte ve bakım işlemleri kolaylaşmaktadır. Bu nedenlerden dolayı marul tohumunun istenmeyen her türlü yabanc1 maddeden temizlenmesi büyük önem arz etmektedir. İstenmeyen materyallerin önemli ölçüde azaltılması veya tamamen kaldırılması ürünün pazar değerinin artırılması için çok önemlidir (Okunola ve ark., 2015).

Ana ürün içerisindeki istenmeyen yabancı materyalin karışımdan ayrılması özellikle tahıl ve yem endüstrilerinde uygulanan işlemlerden biridir. Temizleme ve ayırma işleminin verimliliği ürün kalitesini önemli derecede etkilemektedir (Panasiewicz ve ark., 2008).

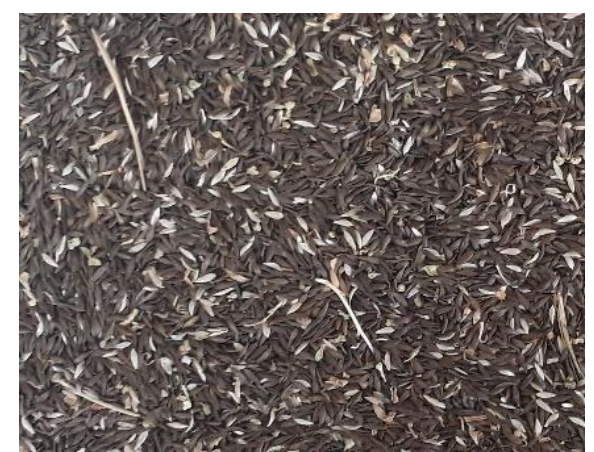

Şekil 2. Marul tohumu ve yabancı madde karışımı

Temizleme ve ayırma işlemleri için kullanılan ekipmanlarda genellikle tohumların boyut, ağırlık, şekil ve aerodinamik özellikleri göz önünde bulundurulmaktadır (Barbos ve Moldovan, 2014). Ayrıca bu özelliklerin bilinmesi tohumların işlenmesi, kurutulması, iletimi, taşınması ve depolanması gibi özel amaçlarla makina, donanım, sistem ve modellerin tasarımı ve geliştirilmelerinde önemli rol oynamaktadır (Özarslan, 2002; Özlü ve Güner, 2016; Dash ve ark., 2008; Razavi ve Milani, 2006; Polyák ve Csizmazia, 2016). Bu bakımdan tohumların boyut, küresellik, projeksiyon alanı, yığın hacim ağırlığı, gerçek hacim ağırlığı, kütle, sürtünme katsayısı ve kritik hız gibi parametreleri ortaya konulmalıdır. 
Boyut (uzunluk, genişlik, kalınlık, aritmetik ortalama çap ve geometrik ortalama çap gibi) ve şekil özelliklerinin ayırma, toplama, boyutlandırma ve ögütme makinelerinin tasarımı için bilinmesi gerekmektedir. Depolama yapılarının boyutlarının belirlenmesinde yığın hacim ağırlığı, gerçek hacim ağırlığı ve bin dane ağırlığı kullanılmakta ve ayrıca bu özellikler yapısal yükleri etkilemektedir. Yı̆̆ılma açısı, depolama ve taşıma araçlarının tasarlanmasında önemli bir kriterdir. Porozite ve yüzey alanı yı ̆̆ın halindeki materyalin hava akımına karşı direncini etkilemekte ve bu özelliklerin bilinmesi kurutma işlemleri için de gerekli olmaktadır (Dash ve ark., 2008).

$\mathrm{Bu}$ çalışmada marul tohumunun geometrik özellikleri (uzunluk, genişlik, kalınlık, geometrik ortalama çap, küresellik, yüzey alanı, projeksiyon alanı), gravimetrik özellikleri (bin dane ağırlığı, yığın hacim ağırlığı, gerçek hacim ağırlığı, hacim, porozite), aerodinamik özellikleri (kritik hız), sürtünme özellikleri (statik sürtünme katsayısı, statik ve dinamik yığılma açısı) ve mekanik özellikleri (kabuk kırılma direnci) belirlenmiştir.

\section{Materyal ve Yöntem}

Denemelerde serbest piyasadan karışık halde tedarik edilen Duna ve Maritima çeşidi marul tohumları kullanılmıştır. Materyal içerisindeki yaprak, sap ve yabancı materyaller elle ayıklanmıştır. Ölçümler Aydın Adnan Menderes Üniversitesi Ziraat Fakültesi Biyosistem Mühendisliği Laboratuvarında gerçekleştirilmiştir.

Denemelerde materyal ağırlığının belirlenebilmesi için $120 \mathrm{~g}$ kapasiteli ve $0,001 \mathrm{~g}$ ölçüm hassasiyetine sahip Denver Instrument marka elektronik terazi kullanılmıştır.

Marul tohumlarının nem içeriğinin belirlenmesi için temiz marul tohumdan hazırlanan 5 örnek $105{ }^{\circ} \mathrm{C}$ sıcaklıktaki etüvde 24 saat bekletilmiştir. Daha sonra örnekler tekrar tartılarak kuru ağırlıkları belirlenmiş ve aşağıdaki eşitlik yardımıyla kuru baza göre nem içeriği hesaplanmıştır:

$$
\operatorname{Nem}(\%)=\frac{W_{0}-W}{W} * 100
$$

Eşitlikte $\mathrm{W}_{0}$ yaş ürün ağırlığ $(\mathrm{g})$ ve $\mathrm{W}$ kuru ürün ağırlığıdır $(\mathrm{g})$.

Marul tohumlarının uzunluk, genişlik ve projeksiyon alanının belirlenebilmesi için rastgele seçilen 500 tane marul tohumunun $1 \mathrm{~cm}^{2}$ lik kalibrasyon yüzeyleriyle beraber fotoğrafları çekilmiştir. Daha sonra bu görüntüler bilgisayara aktarılmış ve Image Tool 3.0 görüntü işleme programı kullanılarak analiz edilmiştir (Saraçoğlu ve Özarslan, 2012).

Marul tohumlarının kalınlıklarının ölçümü manuel gerçekleştirilmiş olup ölçüm için 0,001 mm hassasiyete sahip dijital mikrometre kullanılmıştır. Elde edilen verilerden yararlanarak tohumların geometrik ortalama çap ve küresellik değerleri aşağıdaki formüller kullanılarak hesaplanmıştır (Saraçoğlu ve ark., 2010):

$$
\begin{aligned}
& D_{o}=(L * W * T)^{1 / 3} \\
& S_{p}=\frac{D_{o}}{L}
\end{aligned}
$$

Eşitliklerde $\mathrm{D}_{\mathrm{o}}$ geometrik ortalama çap (mm), L uzunluk (mm), W genişlik (mm), T kalınlık (mm) ve $\mathrm{S}_{\mathrm{p}}$ küreselliktir (\%).

Marul tohumunun bin dane ağırlığını belirleyebilmek için rastgele seçilen 100 tane tohumun kütlesi hassas terazi yardımıyla ölçülmüştür. Ölçümler beş tekrarlı gerçekleştirilmiştir.

Yı̆̆ın hacim ağırlığının belirlenmesinde $100 \mathrm{ml}$ hacmindeki silindirik ölçekli kap kullanılmıştır. Hassas terazide tartılan marul tohumu örneği $150 \mathrm{~mm}$ yükseklikten bu ölçekli kap içerisine dökülmüş ve kap içerisindeki yığının hacmi belirlenmiştir. Bu işlem 10'ar kez tekrarlanmış ve marul tohumunun kütlesinin hacmine oranlanmasıyla yığın hacim ağırlığ $\left(\rho_{b}\right)$ belirlenmiştir.

Gerçek hacim ağırlı̆̆ının belirlenmesi için ise $25 \mathrm{ml}$ hacme sahip piknometre kullanılmıştır. Sıvı olarak yoğunluğu sudan daha düşük olan toluen tercih edilmiştir. Ölçüm 3 kez tekrarlanarak aşağıdaki formül ile tanelerin gerçek hacim ağırlığı hesaplanmıştır (Alayunt, 2000):

$$
\rho_{t}=\frac{m * d_{t}}{m_{t}}
$$

Eşitlikte $\rho_{t}$ gerçek hacim ağırlığı $\left(\mathrm{g} \mathrm{cm}^{-3}\right)$, m örnek ağırlığı $(\mathrm{g}), \mathrm{d}_{\mathrm{t}}$ toluen yoğunluğu $\left(\mathrm{g} \mathrm{cm}^{-3}\right)$ ve $m_{t}$ tanelerle yer değiştiren tolüenin ağırlığıdır $(\mathrm{g})$. 
Gerçek hacim ağırlığı belirlendikten sonra tane hacmi ve porozite aşağıdaki eşitlikler ile hesaplanmıştır (Özarslan, 2002):

$$
\begin{aligned}
& V=\frac{m}{\rho_{t}} \\
& \varepsilon=\left(1-\frac{\rho_{b}}{\rho_{t}}\right) * 100
\end{aligned}
$$

Eşitliklerde $\mathrm{V}$ tane hacmi $\left(\mathrm{cm}^{3}\right)$ ve $\varepsilon$ porozitedir $(\%)$.

Tohumların kritik hızlarının ölçümünde düşey hava kanallı kritik hız ölçüm düzeneğinden yararlanılmıştır (Şekil 3). Hava kanalının üst kısmından bir tohum akış içerisine bırakılmıştır. Hava kanalının üst kısmında açılan deliğe 0-30 $\mathrm{m} \mathrm{s}^{-1}$ ölçüm aralığ 1 ve $0,01 \mathrm{~m} \mathrm{~s}^{-1}$ ölçüm hassasiyetine sahip kızgın telli anemometrenin ölçüm çubuğu yerleştirilmiştir. Tohum akış içerisinde askıda kalana kadar hava debisi artırılmış ve tohumun askıda kaldığı noktada anemometre yardımıyla kritik hız değeri ölçülmüştür (Yalçın ve Özarslan, 2004). Bu ölçümler 50 farklı marul tohumu için tekrarlanmıştır.

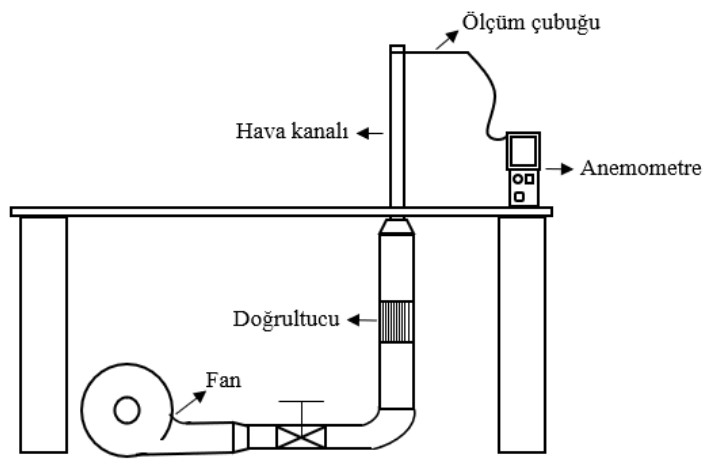

Şekil 3. Kritik hız ölçüm düzeneği (Saraçoğlu ve Özarslan, 2012)

Statik sürtünme katsayısının belirlenmesinde eğimi ayarlanabilen bir ölçüm düzeneği kullanılmıştır (Şekil 4). Düzeneğin yüzeyine $40 \mathrm{~mm}$ çap ve $51 \mathrm{~mm}$ uzunluğa sahip altı ve üstü açık bir örnek kutusu yerleştirilmiş ve kutunun içi marul tohumlarıyla doldurulmuştur. Vidalı bir sistem yardımıyla bu eğimli yüzey, örnek kutusu üzerinden kaymaya başlayana kadar yavaşça yükseltilmiştir. Kaymanın başladığı andaki açı değeri açı ölçerden okunmuştur. Denemeler paslanmaz çelik, alüminyum, kontrplak ve kauçuk olmak üzere dört farklı yüzey üzerinde gerçekleştirilmiş olup ölçüm işlemi her bir yüzeyde $10 \mathrm{kez}$ tekrarlanmıştır (Özarslan, 2002). Statik sürtünme katsayısı aşağıdaki eşitlikten hesaplanmıştır.

$\mu=\tan \alpha$

Eşitlikte $\mu$ statik sürtünme katsayısı ve $\alpha$ eğim açısıdır $\left({ }^{\circ}\right)$.

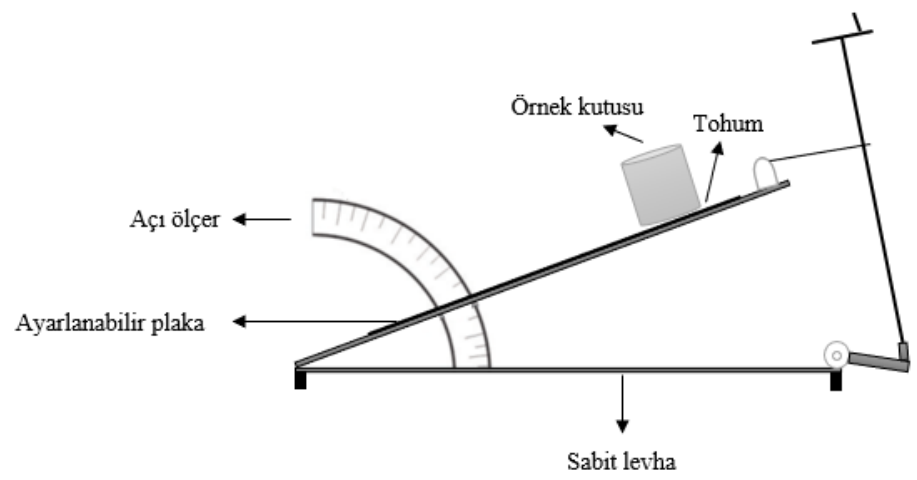

Şekil 4. Statik sürtünme katsayısının belirlenmesinde kullanılan eğik düzlem

Statik yığılma açısı belirlenirken $120 \mathrm{~mm}$ çapında dairesel bir platform kullanılmıştır. $\mathrm{Bu}$ platformun merkezine denk gelecek şekilde $63 \mathrm{~mm}$ çapında ve $90 \mathrm{~mm}$ uzunluğunda bir silindirik boru parçası yerleştirilerek içerisi marul tohumuyla doldurulmuştur. Daha sonra boru parçası yavaşça yukarı doğru kaldırılarak platform üzerinde koni şeklinde bir yığının oluşması sağlanmıştır (Şekil 5). 
Bu ölçüm 20 tekerrürlü olarak gerçekleştirilmiştir. Koninin yüksekliği ölçülerek statik yığılma açısı aşağıdaki eşitlik yardımıyla hesaplanmıştır (Özgüven ve Vursavuş, 2005):

$$
\theta=\tan ^{-1}\left(\frac{2 H}{D}\right)
$$

Eşitlikte H koninin yüksekliği (mm) ve D koninin (platformun) çapıdır (mm).

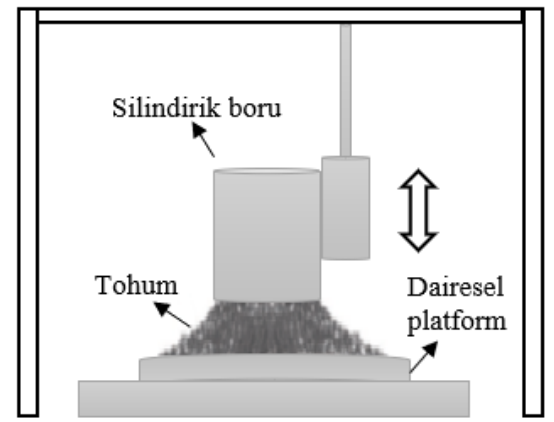

Şekil 5. Statik yı̆̆ı̆lma açısı ölçüm düzeneği

Dinamik yığılma açısı belirlenirken $60 \mathrm{~mm}$ genişliğe ve $70 \mathrm{~mm}$ uzunluğa sahip üstü açık kayar kapaklı bir düzenek kullanılmıştır (Şekil 6). Bu kutunun ön yüzü yukarı aşağı kayar özelliğe sahiptir. Kutu marul tohumu ile doldurulduktan sonra kayar kapak hızlıca yukarı doğru kaydırılmış ve tohum yüzeye bir yığın halinde boşalmıştır. Yığın üzerinde belirlenen iki noktanın düşey $\left(h_{1} v h_{2}\right)$ ve yatay yöndeki $\left(\mathrm{x}_{1}\right.$ ve $\left.\mathrm{x}_{2}\right)$ mesafeleri ölçülerek aşağıdaki eşitlik yardımıyla dinamik yığılma açısı belirlenmiştir (Bart-Plange ve Baryeh, 2003). Ölçüm işlemi 20 kez tekrarlanmıştır.

$$
\emptyset_{d}=\tan ^{-1}\left(\frac{h_{\mathrm{a}}-h_{1}}{x_{\mathrm{z}}-x_{1}}\right)
$$

Eşitlikte $\emptyset_{d d}$ dinamik yığılma açısı $\left(^{\circ}\right), \mathrm{h}_{2}-\mathrm{h}_{1}$ düşey yöndeki mesafe $(\mathrm{mm})$ ve $\mathrm{x}_{2}-\mathrm{x}_{1}$ yatay yöndeki mesafedir (mm).

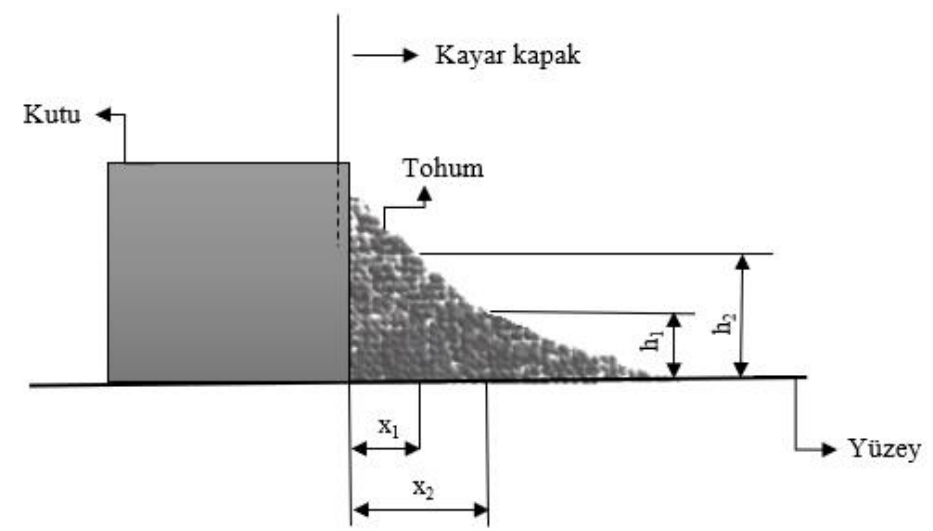

Şekil 6. Dinamik yı̆̆glma açısı ölçüm düzeneği

Marul tohumlarının kabuk kırılma dirençlerinin belirlenmesinde $2 \mathrm{~kg}$ kapasiteli ve $0,01 \mathrm{~kg}$ hassasiyete sahip el penetrometresi kullanılmıştır. 60 farklı tohuma konik uçlu penetrometre ile basma işlemi uygulanmış ve tohumların kırılma anındaki kuvvet değeri ölçülmüştür.

\section{Bulgular ve Tartışma}

Marul tohumlarının kuru baza göre ortalama nem içeriği \%8,09 olarak belirlenmiştir. Marul tohumlarının geometrik özelliklerine (uzunluk, genişlik, kalınlık ve geometrik ortalama çap, küresellik, projeksiyon alanı) ilişkin veriler Çizelge 1'de verilmiştir. Çizelgeye göre marul tohumunun uzunluk değerinin geniş̧lik değerinden 4 kat ve genişliğin ise kalınlık değerinden yaklaşık 1,5 kat daha büyük olduğu söylenebilir. Bu durumda tohumun uzun ve yassı bir şekle sahip olduğu anlaşılmaktadır. Bunun doğal sonucu olarak tohumların küresellik değeri de \%34 olarak belirlenmiştir. Zare ve ark. (2013) kimyon tohumlarının küreselliklerini \%36 olarak belirlemişlerdir. Tohumların uzunluk, 
genişlik ve kalınlıkları arasında büyük farklılıkların olmasından dolayı küreselliğin düşük çıktı̆̆ı ifade edilmiştir.

Marul tohumunun gravimetrik özelliklere ilişkin ortalama veriler Çizelge 2'de sunulmuştur. Marul tohumlarının tane hacmi $0,871 \mathrm{~cm}^{3}$ olarak hesaplanmış ve marul tohumlarının bin dane ağırlığı $1,09 \mathrm{~g}$ olarak belirlenmiştir. Boşluk oranı olarak ifade edilen porozite değeri hem yığın hacim ağırlığına hem de gerçek hacim ağırlığına bağlıdır ve marul tohumlarının yığın hacim ağırlığının düşük olması porozitenin yüksek çıkmasına neden olmuştur.

Çizelge 1. Marul tohumunun bazı geometrik özellikleri

\begin{tabular}{lccc}
\hline \multicolumn{1}{c}{ Özellik } & En Büyük Değer & En Küçük Değer & Ortalama \pm SS \\
\hline Uzunluk (mm) & 4,26 & 2,06 & $3,36 \pm 0,36$ \\
Genişlik (mm) & 1,25 & 0,40 & $0,84 \pm 0,14$ \\
Kalınlı (mm) & 0,72 & 0,25 & $0,54 \pm 0,06$ \\
Geometrik ortalama çap (mm) & 1,40 & 0,63 & $1,15 \pm 0,11$ \\
Küresellik (\%) & 44 & 25 & $34 \pm 0,02$ \\
Projeksiyon alanı $\left(\mathrm{mm}^{2}\right)$ & 4,00 & 1,19 & $2,79 \pm 0,51$ \\
\hline
\end{tabular}

Çizelge 2. Marul tohumunun gravimetrik özellikleri

\begin{tabular}{ccccc}
\hline $\begin{array}{c}\text { Yığın Hacim Ağırlığı } \\
\left(\mathrm{g} \mathrm{cm}^{-3}\right)\end{array}$ & $\begin{array}{c}\text { Gerçek Hacim Ağırlığı } \\
\left(\mathrm{g} \mathrm{cm}^{-3}\right)\end{array}$ & $\begin{array}{c}\text { Tane Hacmi } \\
\left(\mathrm{cm}^{3}\right)\end{array}$ & $\begin{array}{c}\text { Bin Dane Ağırlığı } \\
(\mathrm{g})\end{array}$ & $\begin{array}{c}\text { Porozite } \\
(\%)\end{array}$ \\
\hline 0,463 & 1,153 & 0,871 & 1,09 & 59,84 \\
\hline
\end{tabular}

Yağcıoğlu (1999)'na atfen Berber (2007), yığın hacim ağırlı̆̆ının tohumlar arasında hava boşlukları bulunması nedeniyle gerçek hacim ağırlığından daha düşük olduğunu ifade etmiştir. Çizelge 2 incelendiğinde aynı durumun marul tohumları için de geçerli olduğu görülmektedir. Sacilik (2004) yaptığ çalışmada kuru baza göre \%6,21-\%18,37 nem içeriğine sahip haşhaş tohumlarının yığın hacim ağırlığının 0,5927-0,5583 $\mathrm{g} \mathrm{cm}^{-3}$, gerçek hacim ağırlığının $1,1829-1,141 \mathrm{~g} \mathrm{~cm}^{-3}$, bin dane ağırlığının $0,36-0,43 \mathrm{~g}$ ve porozite değerinin $\% 49,9-\% 51,1$ arasında değiştiğini belirtmiştir.

Marul tohumlarının kritik hız, statik yığılma açısı ve kabuk kırılma direnci değerlerine ilişkin sonuçlar Çizelge 3'te verilmiştir. Marul tohumlarının ortalama kritik hız değeri $3,46 \mathrm{~m} \mathrm{~s}^{-1}$ olarak belirlenmiştir. Nalbandi ve ark. (2010) buğday içerisinde sıkça yetişen bir yabancı ot olan geniş yapraklı pıtrak tohumlarının ve buğdayın aerodinamik özelliklerini belirledikleri çalışmada nemin artmasıyla beraber geniş yapraklı pıtrak tohumunun kritik hızının $6,775 \mathrm{~m} \mathrm{~s}^{-1}$ den $6,877 \mathrm{~m} \mathrm{~s}^{-1}$ ye ve buğday tohumlarının kritik hızının $9,25 \mathrm{~m} \mathrm{~s}^{-1}$ den $9,587 \mathrm{~m} \mathrm{~s}^{-1}$ ye çıktığını belirtmiştir. Gürhan ve ark. (2009) nohudun neme bağlı fiziksel özelliklerini inceledikleri çalışmada nemin kuru baza göre $\% 9,29$ 'dan \%16,82'ye çıkmasıyla beraber kritik hızın da 2,078 $\mathrm{m} \mathrm{s}^{-1}$ den 2,135 $\mathrm{m} \mathrm{s}^{-1}$ 'e yükseldiğini ifade etmişlerdir. Tohumların ortalama statik yığılma açısı $22,55^{\circ}$ olarak hesaplanmıştır. Pradhan ve ark. (2010) keten tohumunun statik yığılma açısını $24,40^{\circ}$ olarak belirlemişlerdir. Marul tohumlarının ortalama kabuk kırılma dirençleri 1,29 kg olarak belirlenmiştir.

Çizelge 3. Marul tohumunun kritik hız, statik yığılma açısı ve kabuk kırılma direnci ölçüm sonuçları (ort \pm SS)

\begin{tabular}{ccc}
\hline $\begin{array}{c}\text { Kritik Hız } \\
\left(\mathrm{m} \mathrm{s}^{-1}\right)\end{array}$ & $\begin{array}{c}\text { Statik Yığılma Açısı } \\
\left({ }^{\circ}\right)\end{array}$ & $\begin{array}{c}\text { Kabuk Kırılma Direnci } \\
(\mathrm{kg})\end{array}$ \\
\hline $3,46 \pm 0,11$ & $22,55 \pm 1,98$ & $1,29 \pm 0,29$ \\
\hline
\end{tabular}

Statik sürtünme katsayısı ile ilgili sonuçlar Şekil 7'de görülmektedir. Marul tohumlarının statik sürtünme katsayısı 0,198 ile en düşük paslanmaz çelik yüzeyde, 0,352 ile en yüksek kauçuk yüzeyde elde edilmiştir. 


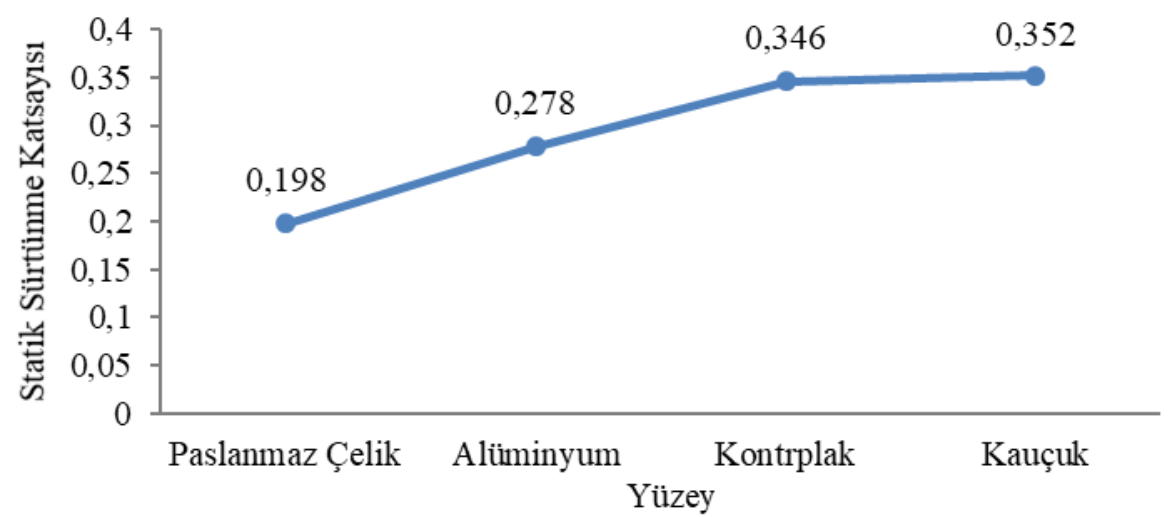

Şekil 7. Statik sürtünme katsayısı değerleri

Çetin ve ark. (2010) turp tohumunun farklı nem içeriklerine göre fiziksel özelliklerini inceledikleri çalışmada statik sürtünme katsayısı için dört farklı yüzeyde (paslanmaz çelik, alüminyum, kauçuk ve galvanize sac) denemeler yapmışlardır. Kuru baza göre \%6,95 nem değerinde statik sürtünme katsayıs1 değerleri, paslanmaz çelikte 0,245, alüminyumda 0,295 galvanize sacda 0,308 ve kauçukta 0,354 olarak bulunmuştur. En düşük statik sürtünme katsayısı değerinin paslanmaz çelikte elde edilmesi nedeninin; paslanmaz çeliğin kullanılan diğer yüzeylere göre daha pürüzsüz ve parlatılmış bir yüzeye sahip olmasından kaynaklandığını belirtmişlerdir. Benzer sonuçlar şeker pancarı tohumu, antepfistığı, karpuz tohumu ve keten tohumu için ifade edilmiştir (Dursun ve ark., 2006; Polat ve ark., 2007; Razavi ve Milani 2006 ve Pradhan ve ark., 2010).

Marul tohumlarının dinamik yığılma açısına ait veriler Şekil 8'de sunulmuştur. Paslanmaz çelik ve kontrplak yüzeyler için bulunan değerler birbirine oldukça yakındır.

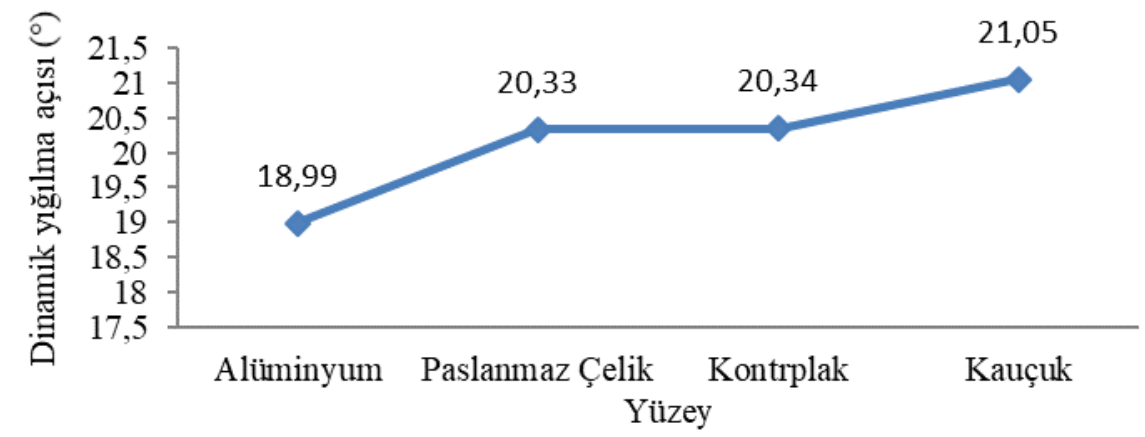

Şekil 8. Dinamik yığılma açısı değerleri

Saraçoğlu ve Özarslan (2012) lahana tohumunun dinamik yığılma açısını belirleyebilmek için kauçuk, alüminyum, plastik ve paslanmaz çelik yüzeylerde ölçümler yapmıştır. Kuru baza göre \%6,86 nem değerinde dinamik yığılma açısı kauçukta $12,41^{\circ}$, alüminyumda $12,31^{\circ}$, plastikte $12,40^{\circ}$ ve paslanmaz çelikte $11,12^{\circ}$ olarak elde edilmiştir. 


\section{Sonuç}

$\mathrm{Bu}$ çalışmada marul tohumunun bazı fiziko-mekanik özellikleri belirlenmiştir. Elde edilen sonuçlara göre marul tohumunun uzunluk, genişlik, kalınlık, geometrik ortalama çap, küresellik değeri ve projeksiyon alanı sirasiyla; $3,36 \mathrm{~mm}, 0,84 \mathrm{~mm}, 0,54 \mathrm{~mm}, 1,15 \mathrm{~mm}, \% 34$ ve $2,79 \mathrm{~mm}^{2}$ olarak bulunmuştur. Tohumların bin dane ağırlığ $1,09 \mathrm{~g}$, yığın hacim ağırlı̆̆ $0,463 \mathrm{~g} \mathrm{~cm}^{-3}$, gerçek hacim ağırlığı $1,153 \mathrm{~g} \mathrm{~cm}^{-3}$, hacmi $0,871 \mathrm{~cm}^{3}$, porozitesi \%59,84 olarak belirlenmiştir. Kritik hiz değeri 3,46 $\mathrm{m} \mathrm{s}^{-1}$ olarak ölçülmüştür. Statik sürtünme katsayısı en düşük paslanmaz çelik, en yüksek kauçuk yüzeyde elde edilmiştir. Dinamik yığılma açısı alüminyum yüzeyde en düşük, kauçuk yüzeyde en yüksek değerde bulunmuştur. Statik yığılma açısı $22,5^{\circ}$ ve kabuk kırılma direnci ise $1,29 \mathrm{~kg}$ olarak belirlenmiștir.

Belirlenen özellikler ticari bir öneme sahip olan marul tohumunun temizleme ve ayırma işlemleri için gerekli olan düzeneklerin ya da makinelerin, depolama yapılarının, depolama ve taşıma araçlarının tasarlama aşamasında ölçülendirilme, malzeme seçimi ve çalışma parametrelerinin belirlenmesinde temel oluşturmaktadır.

\section{Teşekkür}

Bu çalışmanın yürütülmesinde, Aydın Adnan Menderes Üniversitesi Bilimsel Araştırma Projeleri Başkanlığı (BAP) (ZRF-19004) tarafindan verilen destek için teşekkür ederiz.

Not: Bu makale Aydın Adnan Menderes Üniversitesi, Fen Bilimleri Enstitüsü, Tarım Makinaları Anabilim Dalında İpek Çekim'in "Marul Tohumunun Geometrik ve Aerodinamik Özelliklere Göre Ayrılabilirliğinin Araştırılması" adlı Yüksek Lisans Tez çalışmasından üretilmiştir.

\section{Kaynaklar}

Alayunt, F.N., 2000. Biyolojik Malzeme Bilgisi. Ege Üniversitesi Ziraat Fakültesi Yayınları No: 541. 132 s. Bornova, İzmir.

Anonim, 2011. Bileşik Çiçekli Sebzeler Yetiştiriciliği. Milli Eğitim Bakanlığı. Ankara.

Barbos, A., Moldovan, Gr., 2014. The influence of the conditioning system on seed quality. Agricultura. 89: 515.

Bart-Plange, A, Baryeh, Ea., 2003. The physical properties of category B cocoa beans. J Food Eng. 60: 219-227.

Berber, S., 2007. Aspir (Carthamus Tinctorious, L.) tohumlarının aerodinamik özelliklerinin belirlenmesi. Gaziosmanpaşa Üniversitesi Fen Bilimleri Enstitüsü, Tarım Makinaları Anabilim Dalı, Yüksek Lisans Tezi. $47 \mathrm{~s}$.

Çetin, M., Şimşek, E., Akbaş, T., Özarslan, C., 2010. Physical properties of radish (Raphanus sativus L.) seed as a function of moisture content. Philipp Agric Scientist. 93(3): 306-313.

Dash, A.K., Pradhan, R.C., Das, L.M., Naik, S.N., 2008. Some physical properties of simarouba fruit and kernel. International Agrophysics. 22: 111-116.

Dursun, İ., Tuğrul, K.M., Dursun, E., 2007. Some physical properties of sugarbeet seed. Journal of Stored Products Research. 43: 149-155.

Gürhan, R., Özarslan, C., Topuz, N., Akbaş, T., Şimşek, E., 2009. Effects of moisture content on physical properties of black kabuli chickpea (Cicer arietinum L.) seed. Asian Journal of Chemistry. 21(4): 32703278.

Kristkova, E., Dolezalova, I., Lebeda, A., Vinter, V., Novotna, A., 2008. Description of morphological characters of lettuce (Lactuca sativa L.) genetic resources. Horticultural Science (Prague). 35: 113-129.

Nalbandi, H., Seiiedlou, S., Ghassemzadeh, H.R., 2010. Aerodynamic properties of Turgenia latifolia seeds and wheat kernels. International Agrophysics. 24: 57-61.

Okunola, A.A., Igbeka, J.C., Arısoyin, A.G., 2015. Development and evaluation of a cereal cleaner. Journal of Multidisciplinary Engineering Science and Technology. 2: 1587-1592.

Özarslan, C., 2002. Physcial properties of cotton seed. Biosystems Engineering. 83: 169-174.

Özgüven, F, Vursavuş, K., 2005. Some physical, mechanical and aerodynamic properties of pine (Pinus pinea) nuts. Journal of Food Engineering. 68: 191-196.

Özlü, R.R., Güner, M., 2016. Farklı nem düzeylerinde kanola tohumlarının fiziksel özelliklerinin belirlenmesi. Gaziosmanpaşa Üniversitesi Ziraat Fakültesi Dergisi. 33: 10-24.

Panasiewicz, M., Zawislak, K., Kusinska, E., Sobczak, P., 2008. Purification and separation of loose materials in a pneumatic system with vertical air stream. Commission of Motorization and Power Industry in Agriculture. 8: 171-176.

Polat, R., Aydın, C., Ak, B.E., 2007. Some physical and mechanical properties of pistachio nut. Bulgarian Journal of Agricultural Science. 13: 237-246. 
ÇOMÜ Zir. Fak. Derg. (COMU J. Agric. Fac.)

2020: 8 (1): 89-97

ISSN: 2147-8384 / e-ISSN: 2564-6826

doi: 10.33202/comuagri.619355

Polyák, N.I., Csizmazia, Z., 2016. New methodology for measuring the floating velocity of grain particles. Journal of Agricultural Informatics. 7(2): 49-59.

Pradhan, R.C., Meda, V., Naik, S.N., Tabil L., 2010. Physical properties of Canadian grown flaxseed in relation to its processing. International Journal of Food Properties. 13: 732-743.

Razavi, S.M.A., Milani, E., 2006. Some physical properties of the watermelon seeds. African Journal of Agricultural Research. 1(3): 065-069.

Sacilik, K., 2004. Resistance of bulk poppy seeds to airflow. Biosystems Engineering. 89(4): 435-443.

Saraçoğlu, T., Üçer, N., Özyılmaz, Ü., Özarslan, C., 2010. Satsuma mandarin (Citrus unshiu Marc.) çeşidinin sıçrama özellikleri. ADÜ Ziraat Fakültesi Dergisi. 7(1): 87-93.

Saraçoğlu, T., Özarslan, C., 2012. Moisture-dependent geometric, frictional and mechanical properties of cabbage (Brassica oleraceae L. var. capitata) seeds. Philippine Agricultural Scientist. 95(1): 53-63.

Yağcıŏlu, A., 1996. Ürün İşleme Tekniği. Ege Üniversitesi Ziraat Fakültesi Yayınları. No: 517.264 s. İzmir.

Yalçın, İ., Özarslan, C., 2004. Physcial properties of vetch seed. Biosystems Engineering. 88(4): 507-512.

Zare, D., Bakhshipour, A., Chen, G., 2013. Physical properties of cumin and caraway seeds. International Agrophysics. 27: 491-494. 